\title{
SISTEM PENGOLAHAN SAMPAH PASAR MENJADI KOMPOS DENGAN METODE TAKAKURA DI PASAR ALAI PADANG
}

\author{
Darwel, Lindawati, Aidil Onasis, Awalia Gusti \\ (Jurusan Kesehatan Lingkungan Poltekkes Kemenkes Padang)
}

\begin{abstract}
The market is one of the waste-producing places which, if not transported every day, will become a source of disease. The amount of organic waste produced can be processed into compost using a takakura basket. The purpose of this study is to determine the level of knowledge of traders in processing market waste. This type of research is descriptive in which the object under study is organic waste consisting of fruits and vegetables. Data analysis was performed using a table describing the average volume of waste produced per trader every day as well as the level of knowledge of traders on processing market waste into compost. The results of the analysis showed that most traders (52.9\%) had high knowledge about organic waste processing. The average weight of organic waste produced by traders at Alai Padang Market is $9.18 \mathrm{~kg}$ per day and composting time is 30 days. Trash produced by traders can be processed using the takakura method, where the weight reduction effectiveness is more than $80 \%$. It is hoped that Market Managers will always provide directions to traders so that they can process the generated waste first before dumping it into the TPS using the takakura method. It is also hoped that traders will always improve their knowledge in processing the waste produced so that the resulting waste can be of economic value.
\end{abstract}

Keywords: Market Waste; Compost; Takakura

\begin{abstract}
Abstrak
Pasar merupakan salah satu tempat penghasil sampah yang apabila tidak terangkut setiap hari maka akan menjadi sumber penyakit. Banyaknya sampah organik yang dihasilkan bisa di olah menjadi pupuk kompos menggunakan keranjang takakura. Tujuan dari penelitian ini untuk mengetahui tingkat pengetahuan pedagang dalam pengolahan sampah pasar. Jenis penelitian ini adalah deskriptif dimana objek yang diteliti adalah sampah organik yang terdiri dari buah-buahan dan sayur-sayuran. Analisa data dilakukan menggunakan tabel yang menggambarkan rata-rata volume sampah yang dihasilkan per pedagang setiap hari serta tingkat pengetahuan pedagang terhadap pengolahan sampah pasar menjadi kompos. Hasil analisis didapatkan sebagian besar pedagang (52,9\%) memiliki pengetahuan tinggi tentang pengolahan sampah organik. Rata-rata berat sampah organik yang dihasilkan pedagang di Pasar Alai Padang adalah 9,18 kg per hari dan waktu pengomposan selama 30 hari. Kesimpulannya Sampah yang dihasilkan pedagang bisa diolah dengan metoda takakura, dimana efektifitas pengurangan beratnya lebih dari 80\%. Diharapkan kepada Pengelola Pasar untuk selalu memberikan arahan kepada pedagang agar bisa mengolah sampah yang dihasilkan terlebih dahulu sebelum di buang ke TPS menggunakan metode takakura selain itu juga diharapkan kepada pedagang untuk selalu meningkatkan pengetahuannya didalam pengolahan sampah yang dihasilkan sehingga sampah yang dihasilkan bisa bernilai ekonomis
\end{abstract}

Kata Kunci : Sampah Pasar; Kompos; Takakura

Penerbit: Poltekkes Kemenkes Padang, http://jurnal.poltekkespadang.ac.id/ojs/index.php/jsm 


\section{PENDAHULUAN}

Sampah merupakan masalah yang sering terjadi di kota-kota di Indonesia bahkan sampai ke Desa-Desa Terpencil, hal ini terjadi karena masayarakat Indonesia masih banyak yang belum sadar akan dampak dari sampah akibatnya msyarakat akan menghasilkan sampah yang menumpuk dan akan mencemari lingkungan. ${ }^{1}$ Sampah organik adalah sampah yang berasal dari sisa mahkluk hidup yang mudah terurai secara alami tanpa proses campur tangan manusia untuk dapat terurai. Sampah organik bisa dikatakan sebagai sampah ramah lingkungan bahkan sampah bisa diolah kembali menjadi suatu yang bermanfaat bila dikelola dengan tepat. Tetapi sampah bila tidak dikelola dengan benar akan menimbulkan penyakit dan bau yang kurang sedap hasil dari pembusukan sampah organik yang cepat. ${ }^{2}$

Pengelolaan sampah adalah kegiatan sistematis, menyeluruh dan berkesinambungan yang meliputi pengurangan dan penanganan sampah. ${ }^{3,4}$ Pengelolaan sampah yang dapat dilakukan pada sampah basah atau sampah organik untuk mengurangi jumlah sampah yang masuk ke Tempat Pengelolaan Akhir (TPA) diantaranya adalah pengomposan. Salah satu metode pengomposan yang dilakukan adalah menggunakan metode takakura yang mempunyai banyak keuntungannya di antaranya menggunakan peralatan yang sederhana, murah, mudah serta selama pengomposan sangat estetis tidak menimbulkan bau, dan tidak merusak lingkungan. ${ }^{5,6}$

Metode pengomposan dengan menggunakan keranjang takakura ini sangatlah memungkinkan untuk diterapkan karena untuk mengaplikasikan ilmu disamping memberikan kenyamanan untuk masyarakat di lingkungan pasar, juga akan dapat dimanfaatkan untuk pupuk tanaman yang ada disekitar pasar, dan kemudian akan bisa bernilai ekonomis. ${ }^{5,6}$ Sampah di TPS Pasar Alai hanya diangkut satu kali dalam sehari, yaitu pada saat pagi hari sementara pedagang menumpuk sampah di kios-kios begitu saja, dan setiap sore dibawa pengelola ke TPS. Untuk itu dirasa perlu dilakukan penelitian ini sebagai alternatif pengelolaan dan solusi dalam penanganan sampah dan mengolah sampah menjadi barang yang berguna.

\section{METODE PENELITIAN}

Penelitian ini bersifat deskriptif analitik, untuk mengetahui tingkat pengetahuan pedagang tentang pengolahan sampah dan alternatif pembuatan kompos dengan metoda takakura. ${ }^{7}$ Penelitian dilakukan di Pasar Alai Padang dan pelaksanaan direncanakan pada bulan April sampai dengan September 2019.

Objek yang diteliti adalah semua sampah sisa dagangan terutama sayuran dan buahbuahan di Pasar Alai Padang. Populasi dalam penelitian ini adalah seluruh pedagang sayuran dan buah-buahan yang menetap berjumlah 17 pedagang. Sampel adalah seluruh 
pedagang sayuran dan buah-buahan yang berjumlah 17 orang pedagang. Instrumen penelitian ini adalah kuesioner untuk mengetahui tingkat pengetahuan pedagang dan timbangan untuk mengetahui volume sampah yang dihasilkan oleh pedagang.

Data diolah lalu disajikan dalam bentuk tabel distribusi frekuensi untuk dianalisis secara deskripsi tentang gambaran rata-rata volume sampah yang dihasilkan per pedagang setiap hari serta tingkat pengetahuan pedagang terhadap pengolahan sampah pasar menjadi kompos Hasil pembuatan kompos dari sampah dan nilai ekonomisnya dianalisis secara deskriptif sehingga diperoleh gambaran efektifitas penggunaan metoda takakura dalam pengolahan sampah pasar.

\section{HASIL PENELITIAN}

Hasil perhitungan volume sampah pasar yang sudah di lakukan di Pasar Alai Kota Padang adalah sebagai berikut :

Tabel 1. Rata-rata volume sampah yang dihasilkan pedagang di Pasar Alai Kota Padang Tahun 2019

\begin{tabular}{cccccc}
\hline Variabel & $\mathrm{n}$ & Minimum & Maksimum & Mean & Std. Deviation \\
\hline Volume sampah & 17 & 2 & 20 & 9,18 & 5,908 \\
\hline
\end{tabular}

Dari tabel 1 terlihat rata-rata volume sampah yang dihasilkan adalah 9,18 $\mathrm{kg} / \mathrm{hari}$ dengan volume terendah $2 \mathrm{~kg} / \mathrm{hari}$ dan tertinggi $20 \mathrm{~kg} / \mathrm{hari}$.

Tabel 2. Distribusi Frekuensi Pedagang Menurut Tingkat Pengetahuan di Pasar Alai Kota Padang Tahun 2019

\begin{tabular}{llll}
\hline No & Pengetahuan Pedagang & Jumlah & Persentase $(\%)$ \\
\hline 1 & Rendah & 8 & 47,1 \\
\hline 2 & Tinggi & 9 & 52,9 \\
\hline & Jumlah & 17 & 100 \\
\hline
\end{tabular}

Dari tabel 2 terlihat sebagian besar pengetahuan responden tentang sampah organik dan pemanfaatannya menjadi kompos sudah tergolong tinggi yaitu sebanyak 9 orang $(52,9 \%)$. Setelah dilakukan proses komposting menggunakan takakura maka dilakukan penimbangan berat sampah yang dihasilkan baik itu sampah buah-buahan maupun sampah sayur-sayuran. Dari 5 keranjang takakura yang digunakan diperoleh penurunan berat sampah seperti tertera pada tabel 3 dibawah : 
Tabel 3. Pengurangan Berat Sampah Sayur-sayuran dan Buah-buahan Pedagang Sebelum dan Sesudah Komposting di Pasar Alai Tahun 2019

\begin{tabular}{llccc}
\hline \multirow{2}{*}{ No } & Jenis sampah & \multicolumn{2}{c}{ Berat $(\mathrm{Kg})$} & $\begin{array}{c}\text { Persentase } \\
\text { Penurunan Berat }\end{array}$ \\
\cline { 2 - 4 } 1 & Sayur-sayuran & 5 & 0,8 & 84,0 \\
\hline 2 & Buah-buahan & 9 & 1,5 & 83,3 \\
\hline 3 & Sayur-sayuran & 6 & 0,9 & 85,0 \\
\hline 4 & Sayur-sayuran & 8 & 1,3 & 83,8 \\
\hline 5 & Sayur-sayuran & 6 & 1,0 & 83,3 \\
\hline
\end{tabular}

Dari tabel 3 terlihat bahwa penurunan berat sampah sebelum dengan sesudah proses komposting cukup tinggi yaitu mencapai $84 \%$, artinya metode komposting yang digunakan cukup baik.

\section{PEMBAHASAN}

Dari 17 Pedagang yang berjualan sayur-sayuran dan buah-buahan di pasar Alai padang diperoleh rata-rata volume/ berat sampah yang dihasilkan adalah 9,18 $\mathrm{kg} /$ hari dengan berat terendah $2 \mathrm{~kg} /$ hari dan tertinggi $20 \mathrm{~kg} /$ hari. Hasil penelitian ini lebih tinggi dibanding penelitian yang dilakukan oleh Rini Indriyani di Pasar Sampangan yang mendapatkan berat Sampah organik yang dihasilkan pasar sampangan sebanyak 4-10 kg per harinya. Sampah organik lebih banyak dihasilkan pada hari Minggu begitu juga dengan hari hujan karena banyak sayur yang tidak terjual dan membusuk. Sebelum dimasukkan kedalam takakura, sampah tersebut dicacah terlebih dahulu sehingga sampah dalam jumlah banyak bisa dimuat kedalam takakura.

Sampah basah yang dibiarkan berserakan akan menimbulkan gangguan pada lingkungan, menjadi tempat bersarangnya vektor penyakit dan menimbulkan gangguan estetika oleh karena itu para pedagang bisa menjadikannya sebagai kompos. ${ }^{8,9,10}$ Dari hasil penelitian diperoleh sebagian besar pengetahuan responden tentang sampah organik dan pemanfaatannya menjadi kompos sudah tergolong tinggi yaitu sebanyak 9 orang (52,9\%). Penelitian ini sejalan dengan penelitian yang dilakukan oleh Hasniati Sari Harun dimana $58 \%$ pengetahuan responden baik dalam pembuangan sampah walaupun proses pemilahan sampah organik dan an organik masih rendah hanya sebesar $29 \%$. Pengetahuan responden tentang pengelolaan sampah dibangun berdasarkan kemampuan berfikir sesuai dengan kenyataan yang responden lihat dan temukan di lingkungan sekitar responden berada. Oleh karena itu petugas pasar harus tetap memberikan arahan kepada para pedagang dalam pembuangan sampah.

Kompos matang setelah 30 hari, selama masa tersebut kompos harus diaduk dan ditambahkan EM 4 agar mikroorganisme pengurai bisa bekerja dengan baik. Selain itu lakukan pengukuran suhu dimana pada awal proses komposting suhu kompos meningkat dan makin lama suhunya semakin turun. Karena waktunya bisa mencapai 30 hari maka 
takakura bisa disimpan di bawah meja dagangan atau di samping areal TPS sesuai anjuran pengelola pasar. Metode takakura cukup efektif digunakan karena pengurangan berat sampah cukup besar mencapai lebih $80 \%$. Semakin besar penurunan berat sampah berarti akan semakin banyak sampah yang bisa tertampung didalam takakura tersebut. ${ }^{11,12} \mathrm{Hal}$ tersebut dipengaruhi oleh tumpukan sekam dibagian bawah yang mampu menyerap kadar air sampah sehingga sampah dengan cepat berubah manjadi kompos.

Cara baik yang dtempuh untuk mengendalikan volume sampah agar beban TPS tidak semakin berat adalah dengan melakukan $3 \mathrm{R}$ sehingga sampah yang dibuang ke TPA tinggal 35\%. Pengomposan adalah solusi yang dianggap sebagai teknologi berkelanjutan karena bertujuan untuk konservasi lingkungan dan meningkatkan nilai ekonomi sehingga disarankan kepada pengelola pasar untuk dapat menggalakkan pengomposan pada setiap pedagang yang menghasilkan sampah organik. ${ }^{13,14,15}$

\section{SIMPULAN DAN SARAN}

Sebagian besar pedagang (52,9\%) sudah memiliki pengetahuan tinggi tentang pengolahan sampah organik. Rata-rata berat sampah organik yang dihasilkan pedagang di Pasar Alai Padang adalah 9,18 kg per hari. Sampah organik yang dihasilkan oleh pedagang di Pasar Alai bisa dijadikan kompos dalam waktu 30 hari dengan metode takakura. Diharapakan kepada Pengelola Pasar untuk selalu memberikan arahan kepada pedagang agar bisa mengolah sampah yang dihasilkan terlebih dahulu sebelum di buang ke TPS atau TPA. Para pedagang untuk selalu meningkatkan pengetahuannya didalam pengolahan sampah yang dihasilkan sehingga sampah yang dihasilkan bisa bernilai ekonomis.

\section{DAFTAR PUSTAKA}

1. Anwar, Choirul., 2019. Pembuatan Pupuk Kompos dengan Komposter dalam Pemanfaatan Sampah di Desa Bringin Kecamatan Bringin Kabupaten Semarang. LINK, 15(1), 46-49

2. https://www.bulelengkab.go.id/detail/artikel/pengertian-dan-pengelolaan-sampahorganik-dan-anorganik-13. Pengertian dan Pengelolaan Sampah Organik dan Anorganik.[12 Juli 2020]

3. Sahwan, Firman L., 2012. Analisis Proses Komposting pada Pengelolaan Sampah Berbasis Masyarakat Skala Kawasan (Studi Kasus di Kota Depok). Jurnal Teknik Lingkungan, 13(3), 253-259

4. Harun, Hasniati Sari., 2017. Gambaran Pengetahuan dan Prilaku Masyarakat dalam Proses Pemilahan Sampah Rumah Tangga di Desa Hegarmanah. Jurnal Dharmakarya. $6(2), 86-88$. 
5. Indriyanti, Dyah Rini., 2015. Pengolahan Limbah Organik Sampah Pasar Menjadi Kompos. Jurnal Abdimas, 19(1), 43-48.

6. Nofrimon, Agi., 2015. Gambaran Siatem Pengelolaan Sampah dan Alternatif Pengolahannya Di RW 14 Kelurahan Surau Gadang Kecamatan Nanggalo Kota Padang Tahun 2015; KTI. Poltekkes Kemenkes Padang.

7. Notoatmojo, Soekidjo,. 2011. Kesehatan Masyarakat. Jakarta : Rineka Cipta

8. Mulasari, S.A., 2014. Keberadaan TPS Legal dan TPS llegal di Kecamatan Godean Kabupaten Sleman. Jurnal Kesehatan Masyarakat, 9(2), 122-130.

9. Rahmawanti, Novi dan Dony Novrian, 2014. Pembuatan Pupuk Organik Berbahan Sampah Organik Rumah Tangga Dengan Penambahan Aktivator EM4 Di Daerah Kayu Tangi (Formation Organic Compost Fertilizer From Household Waste By Addition of EM4 Activators In Kayu Tangi). Ziraa'ah, 39(1), 1-7

10. Warjoto, Renna Eliana dkk., 2018. Metode Komposting Takakura untuk Pengolahan Sampah Organik Rumah Tangga di Cisauk, Tangerang. Jurnal Perkotaan, 10 (2), 76-90

11. Dahlianah, Inka., 2015. Pemanfaatan Sampah Organik sebagai Bahan Baku Pupuk Kompos dan Pengaruhnya terhadap Tanaman dan Tanah. Klorofil, X (1), 10-13

12. Sahwan, Firman L., 2011. Kualitas Kompos Sampah Rumah Tangga yang di Buat dengan Menggunakan Komposter Aerobik. Jurnal Teknik Lingkungan, 12 (3), 223-240.

13. Yuliananda, Subekti, dkk., 2019. Pemanfaatan Sampah Organik Menjadi Pupuk Kompos Cair Dengan Menggunakan Komposter Sederhana. Abdikarya. 03 (2), 159-165.

14. Darmadi, I Gede Wayan., 2019. Pendampingan Pembuatan Pupuk Organik (Kompos) Cair dari Limbah Rumah Tangga di Kecamatan Selemadeg Timur Kabupaten Tabanan. JPMS, 1 (2), 143-150.

15. Susanti, Diana S., 2015. Pembagian Berbagai Jenis Kompos Pada Pertumbuhan dan Hasil Tanaman Bawang Merah (Allium ascalonicum L) di Kabupaten Enrekang. Agricola. $5(1), 61-69$ 